\title{
Ayşe Betül Oruç, Klasik ve Modern Dönem Tefsir Kaynaklarında Kadın Algısı (Perception of Women in Classical and Modern Commentary Resources), Ankara: Nobel Akademik Yayıncılık, 2020, 2. bs.
}

Sümeyye Sayğın*

Türkiye'de Kur'an-ı Kerim ve tefsir alanında yapılan kadın merkezli çalışmaların birkaç hat üzerinde ilerlediğini söylemek mümkündür. Nispeten erken tarihli çalışmalarda kadın genellikle müstakil bir konu olarak Kur'an-ı Kerim kapsamında ele alınmaktadır (Akdemir, 1997; Fidan, 2006 vb.). Daha sonraki süreçte de kadın başlıca bir konu olarak ele alınmaya devam edilse de yapılan çalışmaların daha hususi nitelikler kazanmaya başladığı anlaşılmaktadır. Bu doğrultuda yapılan çalışmalarda kadınla ilgisi bulunan birtakım konular Kur'an-ı Kerim çerçevesinde ele alınmaktadır (Erdeğer, 2012; Acar, 2018 vb.). Tüm bunlarla birlikte Türkiye tefsir akademisinde kadın merkezli çalışmalar Kur'an Kur'an'la sınırlı kalmamış, müellifler zaman zaman tefsirlerdeki kadın algılarını ortaya koymaya çalışmışlardır. Bu türe ait çalışmaların bazen tarihî bir döneme, bazen tek bir müfessirin tefsirine bazen de birden fazla tefsirin mukayesesine dayandığı görülmektedir (Karslı, 2000; Yüksel, 2016 vb.).

"Klasik ve Modern Dönem Tefsir Kaynaklarında Kadın Algısı" isimli bu çalışma, modern dönem kadın tefsir akademisyenlerinden Ayşe Betül Oruç'a aittir. Yazarın doktora tezi olarak kaleme aldığ bu eser yukarıda değindiğim türlerden ikisini mecz etmektedir.

* Arş. Gör., Necmettin Erbakan Üniversitesi Ahmet Keleşoğlu İlahiyat Fakültesi, Tefsir Anabilim Dalı, sumeyyesaygn@gmail.com, 0000-0001-5778-4174 
$\mathrm{Bu}$ noktada eserin, alanında telif edilmiş önceki çalışmalardan en önemli farkı Hz. Peygamber'den bugüne kadar hazırlanan tefsirlerin büyük çoğunluğunu dikkate almak suretiyle kadınla ilgili ayetler çerçevesinde tefsirlerdeki kadın algısını ortaya koymak, bunu yaparken de klasik ve modern dönem karşılaştırmasına yer vermektir. Dikkat edilmesi gerekir ki yazarın amacı Kur'an-ı Kerim'e göre kadının durumunu veya Kur'an'ın kadına bakışını tespit etmek değildir. Onun nihai amacı tefsir alanında, başlangıçtan günümüze kadar meydana gelen külliyatta kadın konusunun yorumlanma serüvenini ortaya koymak ve klasik-modern dönemi bu minvalde mukayese etmektir. Yazar tefsir kaynaklarının kadına bakışını, müfessirlerin içinde yaşadıkları zaman ve coğrafyanın etkilerini de göz önünde bulundurarak tespit etmiş, her bir konuyu klasik ve modern dönemdeki tefsirler çerçevesinde tek tek ele alarak aralarındaki benzerlik ve farklılıkları anlaşılır bir şekilde aktarmıştır.

Yazarın 2016 yılında tamamlamış olduğu doktora tezinin aynı yılda yayın hayatına kazandırılmasıyla eser, kadın ve tefsir konularında çalışma yapanların, alana ilgi duyanların istifadesine sunulmuştur. Eserin gözden geçirilmiş ikinci baskısı ise 2020 yılında yayımlanmıştır. Giriş dışında üç ana bölümden meydana gelen bu çalışmada klasik ve modern dönemin ayrımında XIX. yüzyılın son çeyreğindeki gelişmeler göz önünde bulundurulmuştur. Zira bu yüzyıl İslam dünyasına yönelik maddi ve manevi birtakım saldırıların yoğunlaştığı ve İslam dünyası âlimlerinin de Kur'an-ı Kerim'den hareketle önlerine çıkan saldırılara cevap vermeye gayret ettikleri bir dönemdir. Netice itibariyle bu çalışmada XIX. yüzyılın son çeyreğinden günümüze kadar telif edilen tefsirler modern, daha önceki tarihlere ait tefsirler ise klasik dönem kaynakları olarak nitelenmiş; çalışma bu iki grup kaynak etrafinda şekillenmiştir.

Eserde üç aşamalı bir metot takip edilmiştir. Ele alınan konuların önce klasik tefsir kaynakları, ardından da modern dönem tefsirleri çerçevesinde nasıl algıılandıkları ortaya konulmuş, ardından her konunun sonuna eklenen bir değerlendirme başlığı altında iki dönemdeki algıların benzerliklerine, farklılıklarına ve varsa orijinal 
yaklaşımlara yer verilmiştir. Müellif, konulara dair tercih ve değerlendirmelerini de bu aşamada yapmıştır. İzlenen bu yöntem, eser bir mukayese çalışması olduğu için isabetli ve anlaşılır olmuştur. Ancak bu durum aynı zamanda başlıklarda ve içerikte, düzenli tekrarlara sebep olmuştur. Kendisi de durumun ayrımında olan yazar, ortaya çıkan bu tekrarların mecburi olduğunu belirtmektedir.

Eserin giriş kısmına "Araştırmanın Kapsamı ve Tarihî Arka Planı" adı verilmiştir. Yazar bu bölümde araştırmanın konusu, amacı ve kapsamına dair bilgi verip klasik ve modern tefsir kaynakları çerçevesinde Cahiliye kadın algısını aktarmıştır. Bilindiği üzere Cahiliye Dönemi ile İslam öncesi Arapların inanışları ve yaşam biçimleri kastedilmektedir. Bu dönemle ilgili son derece dikkat çekici iki konu bulunmaktadır: "Kız çocuklarının hor görülmesi” ve “Allah’ın kızları inanışı”. Kız çocuklarının hor görülmesi, bilhassa bazı Arap kabilelerinde kız çocuklarının diri diri toprağa gömülmesi olgusuna dayanmaktadır. Klasik tefsir kaynakları Cahiliye Araplarının bir kısmında yaygın olan ve Kur'an-ı Kerim'de de haber verilen bu vakıayı söz konusu toplumun kız çocuklarını istememe sebeplerine dikkat çekerek izah etmektedirler. Kur'an-1 Kerim'de kız veya erkek olsun çocukların nimet olma bakımından eşit olarak zikredilişine rağmen klasik dönem kimi tefsir kaynaklarında bu tür ayetlerin erkek lehine yahut erkeğin üstünlüğünü kabul edici bir yaklaşımla yorumlanması ilginçtir. Oysa ayetler Cahiliye Araplarında kız çocuğuna yaşam hakkı tanımayan yahut onu ömür boyu hakir görülmeye mahkûm bırakan bu uygulamaların yanlışlığını ve suçsuz günahsız yere öldürülen kız çocuklarının haklılıklarını öne çıkarmaktadır. Allah'ın kızları inanışı ise müşrik Arapların melekleri Allah'ın kız çocukları olarak kabul etmelerini ifade eder. Kendilerine kız çocuklarını layık görmeyen bu kimselerin melekleri kız çocuğu olarak Allah’a nispet etmeleri çelişkili bir durumdur. Nitekim Kur'an-ı Kerim'de onların bu taksimatındaki çarpıklık vurgulanmaktadır (İsrâ 17/40; Sâffât 37/149-159). Klasik tefsir kaynaklarının bir kısmı Cahiliye Araplarının Allah’a kız çocuğu isnat etmesini -O’na bir çocuk isnat etmenin yanlışlığını vurgulamak yerine- erkeğe göre eksik kabul edilen kız çocuğunun Allah’a 
isnadındaki yanlışlıkla izah etmektedir. Bu iki açıklama göstermektedir ki klasik dönem müfessirlerin bir kısmı erkeği önceleyen ataerkil bakış açısıyla ayetleri değerlendirmekte ve ayetlerdeki temel mesajı geri plana atmaktadırlar. Modern dönem tefsirlerine bakıldığında ise kız çocuklarının hor görülmesi neticesindeki yanlış uygulamalara karşı İslam dininin getirmiş olduğu düzenlemelerin ön plana çıkarıldığı görülmektedir. Modern kaynaklar ilgili ayetlerde vurgulanan temel esasın kız olsun erkek olsun yaratılmış her insanın öncelikle Allah'ın bir kulu olduğunu aktarır. Oruç Kur'an-ı Kerim'in ilgili ayetlerinin Cahiliye Dönemi’nde kız çocuğuna/kadına bakışı ortaya koyma anlamı taşıdığını, Kur'an'ın kadın veya erkeği tercih eden bir yoruma gitmediğini belirterek ana mesajlara odaklanmak gerektiğinin altını çizmektedir.

"Yaratılış ve Cennetten Çıkarılma” adı verilen birinci bölümde kadının yaratılışı, "nefs-i vahide", "çiftler halinde yaratılma" ve "bir erkek-bir kadından yaratılma" konuları çerçevesinde ele alınmaktadır. Yazar ilk olarak kadının yaratılışını ele almasının sebebini kadının İslam'daki yeri ve konumu hakkında oluşan görüşlerin kadının dünya hayatında var olma serüvenine verilen anlamlara dayanmasıyla açıklar. Yaratılma konusu ise nefs-i vahide kavramı ele alınarak başlatılmaktadır. Zira ayet-i kerimede ilk olarak insanların tek bir nefisten yaratıldığı, eşinin de ondan var edildiği belirtilmektedir (Nisâ 4/1 ). Klasik kaynakların önemli bir kısmında nefs-i vahide Hz. Âdem olarak kabul edilmektedir. Eşinin yani kadının da nefs-i vahideden yaratıldığının haber verilmesi klasik kaynaklarda baskın bir biçimde Havvâ'nın Âdem'in kaburga kemiğinden yaratıldığı şeklinde anlamlandırılmaktadır. Klasik tefsir kaynaklarında müfessirlerin bu düşüncelerini bazı hadis rivayetlerine dayandırdıkları görülmektedir (Buhârî, "Enbiyâ", 1). Modern dönem tefsir kaynaklarında ise Havvâ'nın Âdem'in kaburga

1 Ey insanlar! Sizi bir tek nefisten yaratan ve ondan da eşini yaratan, ikisinden birçok erkek ve kadın yaratıp yayan Rabbinize itaatsizlikten sakının. Adını anarak birbirinizden dilek ve istekte bulunduğunuz Allah'a saygisızlıktan ve akrabalık haklarına riayetsizlikten de sakının. Şüphesiz Allah sizin üzerinizde gözetleyicidir." Nisâ 4/1. 
kemiğinden yaratıldığı görüşü eleştiriye tâbi tutulmuştur. Zira kadının erkekten yaratılmış olduğunun kabul edilmesi erkeği ilk yaratılan ve kâmil, kadını ise ikinci yaratılan ve tam olanın bir parçası kılan yaklaşımdır. Bu durumda erkek sürekli olarak üstün ve eksiksiz bir konumda olurken kadın hiçbir zaman onunla eşit olmamaktadır. Yazar, yaratılış konusunda nefs-i vahideye yani tek bir asla vurgu yapan ayetlerde Allah Teâlâ'nın kadın veya erkek olarak bir şahsa işaret etmediğini, hangisinin önce yaratıldığına dair bir ifadeye yer vermediğini esasen öze yani insan olma vasfına dikkat çektiğini vurgulamaktadır. Yani yaratılışı konu edinen ayetlerde öne çıkan mesaj insan olma özü ve bu bağlamda tüm insanların tek bir asla dayandırılmış olduğudur. Ayrıca klasik kaynaklarda kadının, erkeğin kaburga kemiğinden yaratıldığına dair yer verilen görüşleri destekleyen herhangi bir karine de Kur'an-ı Kerim'de yer almamaktadır.

Birinci bölümün ikinci konusu kadının cennetten çıkarılması meselesidir. Bilhassa klasik tefsir kaynaklarında bu konu çoğunlukla kadın merkezli yorumlanmaktadır. Kaynaklarda konuyla ilgili rivayetlerin çok sayıda ve etkin olduğu görülmektedir. Buna göre hâkim olan algı yasaklanan ağaçtan önce Havvâ'nın yediği, sonra Âdem'e yedirdiği ve böylelikle cennetten çıkarılmanın suçlusunun kadın olduğu yönündedir. Yine klasik kaynaklarda bu durumun kadının fitne ve imtihan sebebi olmasının temelini oluşturduğu da öne çıkan bir düşüncedir. Modern dönemde ise cennetten çıkarılma konusunda sorumluluk kadına yüklenmemekte; şeytanın insana düşmanlığı, insanın Allah'a itaatinin gerekliliği, yasaklardan kaçınma gibi ana mesajlara odaklanmanın gerekliliği vurgulanmaktadır. Yazar detaylı bilgilere yer verdikten sonra şu neticeye varmıştır: Kur'an, cennetten çıkarılma kıssasını ayrıntılarına girmeden ve önemli mesajlarla birlikte sunmaktadır. Klasik tefsir kaynaklarının çoğunda ve modern dönemdeki bazı yaklaşımlarda kendisine yer bulan kadını suçlayıcı tavrın ise büyük ölçüde Tevrat'ta yer alan ifadelere, İsrâilî birtakım haberlere ve ataerkil toplum yapısının bazı kabullerine dayandığı anlaşılmaktadır. Kur'an ayetleri dikkatle 
incelendiğinde görülmektedir ki cennetten çıkarılma konusundaki sorumluluk Âdem ve eşine eşit olarak verilmektedir.

Yazar, aile hayatında kadın ile ilgili konulardan oluşan eserin ikinci bölümünü ikiye ayırmış; evlilik sürecinde ve boşanma sürecinde kadın konusunu art arda işlemiştir. Evlilik süreci en başından itibaren ele alınmış; eş seçimi, mehir, çok eşlilik, gayr-i müslimle evlilik ve annelik konularındaki algılar ilgili ayetler ışığında ortaya konulmuştur. Bahsi geçen konular klasik müfessirler tarafindan büyük ölçüde İslam hukuku çerçevesinde ele alınmaktadır. Buna göre ayette dörde kadar kadınla evlenebilme ifadesi aynı anda en fazla dört hanımla evlenmenin mümkün olduğuna dair bir sinırlama getirmektedir. Bu konuda eşler arasında maddi konularda adaletin sağlanması gerektiği vurgulanmaktadır. Birden fazla evliliğe müsaade eden ayetlerde ise modern dönem tefsirlerinde adaletin sadece maddi konularda değil aynı zamanda sevgi, şefkat, ilgi gibi manevi hususlarda da gerekli olduğuna dikkat çekilmektedir. Ayrıca birden fazla evliliğin; maddi-manevi her konuda eşler arasında adaletin tam manasıyla sağlanmasının neredeyse imkânsız olmasından ötürü çok istisnai durumlarda gerçekleşebileceğinin altı çizilmektedir. Boşanma hayatıyla ilgili olarak kavvâm, derece, tafdîl lafızları, talak, iddet ve muhâlea konuları ele alınmaktadır. Erkeğin kavvâmlığı bağlamında kadının dövülmesi bahsine detaylı olarak yer verilmektedir. Klasik ve modern kaynaklar kadına eziyet veren can yakan bir dövmenin hak olmadığı, Hz. Peygamber'in de hanımlarını döven kimselerin bu fiillerini kerih gördüğü konusunda ittifak etmektedirler. Ancak klasik dönemde, erkeğin kavvâm oluşu kadına karşı mutlak üstünlüğü olarak algılanmakta ve erkeği önceleyen kadını geri planda bırakan bir anlayış hâlini almaktadır. Modern dönemde ise kavvâmlık vasfi erkeğin koruyup gözeten, geçimi üstlenen konumda oluşuyla izah edilmektedir. Bu durum son asırda kadın konusundaki pozitif yönde değişen bakış açısının ve yaşanan gelişmelerin modern tefsirlere olan etkisini göstermektedir.

Eserin üçüncü bölümü “Toplumsal Hayatta Kadın” konusuna ayrılmış; toplumsal hayatın ayrılmaz parçaları olan dinî ve siyasi 
hayata yer verilmiştir. Yazar dinî hayatta kadın bahsinde kadınların özel hâli ve ibadetleri, Cuma namazı gibi meseleleri incelemiştir. Klasik kaynakların kadınların özel hallerinde (regl döneminde) ibadet etmemelerini onların dindeki eksikliği olarak yorumlamalarında konuya dair meşhur bazı rivayetler etkili olmaktadır (Buhârî, "Hayz", 7). Ancak kadının adet halinden bahsedilen ayette (Bakara 2/222) kendisiyle ilgili herhangi bir eksiklik imasına yer verilmemesi bu noksanlık ithamının asılsız olduğunu göstermekte ve kadını eksik gören bu yaklaşım Kur'ânî ilkelerle ters düşmektedir. Nitekim Allah tarafından kadına verilmiş ve çocuk sahibi olmada gerekli bir hal neticesinde Allah'ın emrettiği ibadetleri yerine getirmemiş olması kadını Allah'a olan ibadet yükümlülüğünde yetersiz kılmayacaktır. Ayrıca İslam'da kadın adet halindeyken -bazı başka din ve inançlarda olduğunun aksine- kesinlikle pis kabul edilmemiş, bu zamanlarda toplumdan uzaklaştırılmamıştır. Kadının adet hali Kur'an'da “eziyet”, "sıkıntılı bir hal” olarak nitelenmekte, bu dönemde kadının fiziksel ve psikolojik olarak hassas olduğuna işaret edilmektedir (Bakara 2/222). Kur'an'ın bu duruma değinmesi konunun hem kadın hem de erkeğe bakan bir cihetinin bulunduğunu göstermektedir. Erkeklere bu dönemlerde uymaları gereken bazı kurallar tayin edilmiş ve sınırlar belirlenmiştir. Bununla birlikte Hz. Peygamber'in hanımlarıyla adet dönemlerindeki münasebeti noktasinda nakledilen haberler, erkeklerin bu dönemlerinde hanımlarına karşı tavırlarında dikkate almaları gereken mühim misaller sunmaktadır.

Siyasal hayatta kadın konusu "kadınların bey'ati, velayeti ve Sebe Melikesi" hakkındaki ayetler çerçevesinde işlenmiştir. Zira kadınların siyasi hayattaki konumlarını doğrudan belirleyen ayetler bulunmamakla birlikte, ilgili ayetlerin tefsirlerinde kadının siyasi hayattaki konumu ve idareciliği meselelerine değinilmektedir. Kadınların bey'ati ${ }^{2}$ meselesi de Mekke'nin fethinin ardından Mekkeli kadınların Hz. Peygamber'e gelerek onun yöneticiliğini

2 Bey'at (biat), siyasi hayatta yöneticinin kabul edildiği, kendisine bağlılığın sunulduğu bir akittir. Ticarette iki tarafın anlaştığının bir göstergesi olan el sıkışma geleneğinin siyasi hayattaki yansıması gibi düşünülebilir. 
kabul ettiklerine dair kendisine bey'at etmelerinden bahseden ayet-i kerime (Mümtehine 60/12) bağlamında yorumlanmaktadır. Hz. Peygamber'in aynı zamanda devlet başkanı olmasından ötürü kadınlardan da bey'at alması toplumsal hayatta kadının siyasi bir etkinliğinin bulunduğunun açık bir göstergesidir. Kadının siyasi hayattaki yerine dair Kur'an'da bahsi geçen bir başka husus da kadının yöneticiliği meselesidir. Bilhassa devlet başkanlığı vasfı bulunan bir kadın olması ve hakkında detaylı bilgilere yer veren ayetlerin varlığından ötürü Sebe Melikesi'ne (Belkıs) (bk. Neml 27/22-44) klasik ve modern dönem tefsirlerinde önem verildiği görülmektedir. Kur'an ayetlerinde Melike'nin yöneticiliğini nefyeden ifadeler bulunmamasına karşın kadının yönetici olduğu bir toplumun kurtuluşa eremeyeceğine dair nakledilen birtakım olumsuz rivayetlere (bk. Tirmizî, "Fiten", 75) dayanarak klasik kaynaklar kadının yöneticiliğini olumsuzlayan bir algıyı yansıtmaktadırlar. Bu yaklaşıma göre Belkıs’ın yöneticiliği hakkında haberler veren bu kıssa kadının yöneticiliğinin caiz olduğunu göstermemektedir. Zira o ve tebaası onun yöneticiliği esnasında mümin değildirler. Dolayısıyla onların fiilleri müminler için delil teşkil etmemektedir. Modern dönemde ise tefsir kaynakları yöneticilikte cinsiyetin değil ehliyet ve liyakatin öne çıkarılması gerektiğine vurgu yapmaktadırlar. Nitekim Oruç da Kur'an-ı Kerim'de yönetimle ilgili bahislerde iki cinsiyetten herhangi birine vurgu yapılmadığını, bu konuda en önemli iki ilkenin ehliyet ve adalet olarak vurgulandığını belirtmektedir. $\mathrm{Bu}$ nedenle yöneticilik konusunda gereken şartları taşıdıkları müddetçe erkek ve kadının yöneticilik noktasında eşit hak sahibi olduğunu söylemek isabetli olacaktır.

Değerlendirmesini yaptığım Klasik ve Modern Dönem Tefsir Kaynaklarında Kadın Algısı isimli bu çalışmada yazar Ayşe Betül Oruç çă̆ımızda kadına dair tartışmalı pek çok konuyu ele almıştır. Yazar, Hz. Peygamber'den itibaren tarihî süreç içerisinde -klasik ve modern tefsir kaynaklarında- bu konuların nasıl değerlendirildiğini bütüncül bir şekilde gözler önüne sermektedir. Alanındaki diğer çalışmalardan farklı olarak kendisine tefsir külliyatının büyük çoğunluğunu çalışma sahası edinmiştir. Bu yönüyle eser hem Kur'an'da 
kadın konusunun nasıl ele alındığını hem de klasik ve modern dönemde müfessirlerin konuya dair yaklaşımlarını görmek isteyenler için ufuk açıcı bir niteliğe sahiptir. Birçok konuda Oruç, klasik dönem tefsir kaynaklarından farklı kanaatler benimsemekte ve görüşleri genellikle modern dönem tefsir kaynaklarıyla örtüşmektedir. Yazar, erkeği önceleyip kadını dışlayan herhangi bir yaklaşıma katılmamaktadır. Ona göre ilgili ayetlerde odaklanılması gereken esas nokta Kur'an'ın temel mesajı ve ilkeleridir. Zira Kur'an bahsi geçen konularda cinsiyeti önceleyen ifadelere yer vermemekte; bu konuların özüne vurgu yapmaktadır.

Eserin Kur'an ve tefsir akademisine yapmış olduğu bir diğer önemli katkı da klasik ve modern dönem mukayeseli çalışmalar yapma gayretinde olan araştırmacılara metot örnekliğidir. Kadın konusunda olduğu gibi tartışmalı pek çok konuda tefsir literatüründeki yaklaşımları mukayeseli olarak ortaya koymak isteyenler bu çalışmadan yöntem bakımından istifade edebilecektir. Tüm bunların yanında Türkiye'de kadın ve tefsir eksenli yapılan çalışmaların azlığı ve bu konuda verilen eserlerin çoğunlukla erkek akademisyenler tarafından kaleme alınmış olması göz önünde bulundurulduğunda kadın bir tefsir akademisyen tarafından yapılmış kapsamlı çalışma olması, kitabın literatürdeki kıymetini perçinlemektedir.

\section{Kaynakça}

Acar, H. İ. (2018). Kur'ân'a Göre Kadın ve Siyaset. Turkish Studies, 13(26), 19-41. DOI:10.7827/TurkishStudies.14280.

Akdemir, S. (1997). Tarih Boyunca ve Kur'ân'ı Kerim'de Kadın. İslâmî Araştırmalar, 10(4), 249-258.

Erdeğer, B. (2012). Yasak Meyve Bağlamında Kadının Konumunun Kur'ân Açısından Değerlendirilmesi. (Yüksek Lisans Tezi. İstanbul Üniversitesi, İstanbul).

Fidan, H. (2006). Kur'an'da Kadın İmgesi. İstanbul: Vadi Yayınları.

Karslı, İ. H. (2000). Kur'an Tefsirinde Sosyo-Kültürel Çevrenin Rolü ve Bu Bağlamda Türkiye Örneğinde Kadın. (Doktora Tezi. Atatürk Üniversitesi, Erzurum).

Yüksel, Y. (2016). İbn Âşûr Tefsirinde Siyaset Toplum ve Kadın. İstanbul: Rağbet Yayınları. 